\title{
Speaker commitments: Presupposition *
}

\author{
Stanley Peters \\ Stanford University
}

\begin{abstract}
The familiar view that presuppositions are a variety of speaker commitment is supported by the deviance that results from presupposing something while undertaking incompatible commitments. Speaker commitments differ from other speaker meaning in not being cancelable in discourse contexts that conflict with them. Similarities and differences in projection patterns of presuppositions and conversational implicatures - the latter are speaker meaning but not speaker commitments - reveal both the ease with which projected conversational implicatures and their ilk can be mistaken for presuppositions, and also the importance of not confounding them. Recent proposals (Simons, Tonhauser, Beaver \& Roberts 2010; Simons, Beaver, Roberts \& Tonhauser 2016) for a unitary account of all projective content make projected presuppositions speaker meaning that is not a speaker commitment. In addition to this problem, the proposals rest on a faulty generalization about conditions in which projection occurs.
\end{abstract}

Keywords: presupposition, speaker commitment, projection

\section{Varieties of speaker commitments and speaker meaning}

\subsection{Presuppositions are speaker commitments}

Speech acts that utilize an expression with a presupposition commit their speaker to presupposed propositions being true. This widely noted and generally accepted fact is what originally led scholars to the question of how presuppositions differ from other varieties of speaker commitment.

Consider an example. A speaker who asks (1),

(1) Was it Huck who dipped Becky's pigtail in the inkwell?

commits herself to the truth of (2).

(2) Someone dipped Becky's pigtail in the inkwell.

Asking the question makes this commitment even though the speaker is not committed to any stance on the issue of whether Huck did or didn't dip Becky's pigtail in the inkwell. Exactly parallel observations hold of a speaker who states (3).

* I thank Cleo Condoravdi and Lauri Karttunen for comments on this work. 
(3) If it was Huck who dipped Becky's pigtail in the inkwell, then the teacher punished the wrong pupil.

Unlike statement (4),

(4) It was Huck who dipped Becky's pigtail in the inkwell.

which cannot be true unless (2) is, ${ }^{1}$ question (1) does not entail (2)-questions not ever being true, or for that matter false. Nor does conditional (3) entail that Huck dipped Becky's pigtail in the inkwell, thereby commiting the speaker to (2). Of the trio (1), (3), (4) of sentences, only (4) commits its speaker to Huck having dipped Becky's pigtail in the inkwell. Thus the presupposition (2), which all three expressions are generally taken to share, is not necessarily entailed by sentences that presuppose it - although it can be entailed in addition to being presupposed, as is the case with (4). Even (5), which also commits its speaker to (2), can arguably be true without (2) being true.

(5) It wasn't Huck who dipped Becky's pigtail in the inkwell.

The pattern of presuppositions constituting speaker commitments across these transformations of a declarative sentence is a useful diagnostic. It strikingly differentiates presuppositions from declarative sentences' assertive content, which is not generally shared by their negation, the question formed from them, and conditionals with them or their negation as antecedent. Of course, the fact that presuppositions, such as the one triggered by the cleft construction, are quite generally shared by related sentences does not in itself explain how presuppositions differ from other varieties of speaker commitment. Rather it needs to be explained in terms of some deeper distinction between presupposed and assertive content.

The Family of Sentences (FOS) Test for presupposition, as it is sometimes called, is often expanded to include additional related sentences such as (6), with a possibility modal, and others as well.

(6) Maybe it wasn't Huck who dipped Becky's pigtail in the inkwell.

Although the FOS test is quite useful for distinguishing what a declarative clause asserts from other types of propositional content associated with the clause, it is not determinative for presupposition, as section 1.2 discusses.

Before going there, though, let us take care to be certain we have not too easily conceded that speech acts utilizing sentences (1), (3), (5), and (6) commit their speaker to (2) being true. First we note the obvious fact that even in a conversation where no party is committed to defend the truth of (2) until someone performs a speech act with (1), (3), (4), (5), or (6), once the speech act is made the speaker

1 If Huck dipped Becky's pigtail in the inkwell, it follows that someone did. 
Presupposition

is committed to (2). She cannot disavow the commitment without contradicting herself. This is what makes discourse (7) deviant, except when the question expresses skepticism concerning an earlier proposal that Huck dipped Becky's pigtail in the inkwell.

(7) Was it Huck who dipped Becky's pigtail in the inkwell? (\#)I'm not sure anyone did.

It is quite generally anomalous to perform a speech act and then commit to a conflict with its presuppositions. Only when the initial speech act can naturally be understood as not actually committing its speaker to what the expression used would otherwise presuppose is such a discourse felicitous. What Horn (1989) calls metalinguistic negation is parallelled with metalinguistic questions, as (7) illustrates. A corresponding example with negation would be (8).

(8) It wasn't Huck who dipped Becky's pigtail in the inkwell. (\#)I'm not so sure anyone did.

Stating (8) is anomalous unless prior context includes some kind of suggestion that Huck dipped Becky's pigtail in the inkwell. The contrast between $(7) /(8)$ and $(9) /(10)$ is illuminating.

(9) Was it Huck who dipped Becky's pigtail in the inkwell? I'm sure he didn't.

(10) It wasn't Huck who dipped Becky's pigtail in the inkwell. I'm sure he didn't.

Both (9) and (10) are fully acceptable in contexts where it has been proposed that someone dipped Becky's pigtail in the inkwell. Their felicity does not depend on any prior suggestion or proposal that Huck is the culprit, and they both commit their speakers to the presupposition (2). Indeed, they recommit their speaker to this proposition even if she committed herself to it earlier; it's immaterial who previously proposed (2).

So the felicity conditions of (7) and (8) reveal a subtlety in practical application of the FOS Test. So-called metalinguistic negatives and metalinguistic questions need not inherit all presuppositions of the affirmative declarative sentence they are related to. These special cases seem not to constitute a failure of presuppositions to pass the FOS Test but instead to be cases in which propositions that would ordinarily be presupposed are not, and instead fall with other content in the scope of negation or querying.

Additional evidence reinforcing that speakers are committed to the presuppositions of expressions they use in speech acts is this: explicit contradiction occurs when these speakers contemporaneously have other commitments that are inconsistent with the presuppositions. For example, discourse (11) would be deviant regardless of what context it occurred in. 
(11) No one dipped Becky's pigtail in the inkwell. \#Was it Huck who did it?

When a speaker commits to some proposition then makes a speech act having a presupposition inconsistent with that proposition, her self-contradiction is powerfully evident. In such cases, even a metalinguistic use of questions is excluded; it would call into question the speaker's immediately preceding commitment. An equally strong direct contradiction arises, resulting in a similar degree of infelicity, when a speaker first performs a speech act then commits to something contradicting its presupposition.

(12) Was it Huck who dipped Becky's pigtail in the inkwell? \#Nobody did. ${ }^{2}$

The strong contradictions in (11) and (12) show that speakers are committed to propositions their utterances presuppose. So theories of presupposition must be consistent with presuppositions actually being speaker commitments-indeed, they should account for this fact.

\subsection{Conversational implicatures and the FOS test}

Conversational implicatures differ from presuppositions in key respects. However, they have enough similarities to create potential for confusion.

Grice (1989) convincingly demonstrated that speakers can successfully mean and communicate certain propositions their speech acts do not commit them to, and introduced the term conversational implicature for such propositions. On Grice's theory, and most subsequent elaborations of it, conversational implicatures arise when a listener must recognize on certain pragmatic grounds that the speaker likely believes these propositions: were the speaker not to believe them, general or particular features of the current conversational context could not be adequately reconciled with the hypothesis that the speaker's speech act fulfills requirements for the communicative action to be rational.

2 Interestingly, metalinguistic negation seems more capable of rescuing felicity in cases like these. Discourse (i) is perhaps an acceptable way of disagreeing with someone else's earlier statement that Huck dipped Becky's pigtail in the inkwell.

(i) No one dipped Becky's pigtail in the inkwell. (\#)It wasn't Huck who did it.

In this case, it appears to be rhetorically felicitous to follow up a broad initial refutation with a more specific metalinguistic negative statement to reinforce the point of disagreement. It may also be rhetorically acceptable to place the broader assertion after the metalinguistic negative statement when disagreeing with another's claim that Huck dipped Becky's pigtail in the inkwell.

(ii) It wasn't Huck who dipped Becky's pigtail in the inkwell. (\#)No one did. 
Presupposition

Conversationally implicated propositions, though meant by the speaker, are no part of the linguistic meaning of the expression uttered. Nor does the speech act commit the speaker to them being true. The latter fact is the reason why conversational implicatures (i) do not arise in the first place if the speaker is seen to be committed to something incompatible with them and (ii) also are not present-in Grice's terminology are cancelled-if the speaker follows up a speech act that could conceivably conversationally implicate them with a commitment that is incompatible. Consider some examples. Statement (13),

(13) Some students passed the course.

quite generally conversationally implicates that some students didn't pass, and statement (14A),

(14) Q: Shall we go to the movies tonight?

A: I have an exam tomorrow.

conversationally implicates in discourse (14), though not in general, that the respondent won't go to the movies. Because speakers are not committed to either implicature, no anomaly exists in discourse (15) or answer (16A).

(15) Some students passed the course. In fact, all did.

(16) Q: Shall we go to the movies tonight?

A: Sure, though I need to study for an exam tomorrow.

The conversational implicature that would likely have been communicated had these speakers not committed themselves to something incompatible with it simply does not arise. The existence of an incompatible proposition does not render these discourses deviant, as would happen if speech acts committed their speaker to propositions that could be conversationally implicated. This contrasts sharply with the behavior presuppositions manifested in discourses (11) and (12). Potential conversational implicatures simply fail to actualize when they would conflict with speaker commitments. Discourses (15) and (16) do not even require special preconditions for felicity like (7) and (8) in order to avoid deviance. Plainly, conversational implicatures never are speaker commitments.

Many conversational implicatures that speakers generally mean to convey with an expression such as the quantificational determiner some, though no part of the expression's linguistic meaning, nevertheless have a strong association with it. This is why the discovery that conversational implicatures are not part of these expressions' meaning has had such a transformative impact on linguistic semantics and the philosophy of language. Interestingly, when a clause containing such an expression is embedded in a larger construction, generalized conversational implicatures often 
seem to project to the resulting sentence. For example, many English speakers judge that all four sentences in (17),

a. Jim was forced to whitewash the fence.

b. Jim wasn't forced to whitewash the fence.

c. If Jim was forced to whitewash the fence, Tom should be punished.

d. Was Jim forced to whitewash the fence?

share an implication that Jim whitewashed the fence. As the data in (18) show, only (17a) actually commits its speaker to this proposition, indicating that the implication in question is something like a conversational implicature associated with the verb force and is definitely not a presupposition. ${ }^{3}$

a. Jim was forced to whitewash the fence \#but he didn't whitewash it.

b. Jim wasn't forced to whitewash the fence and he didn't whitewash it.

c. If Jim was forced to whitewash the fence, Tom should be punished; but Jim didn't whitewash it.

d. Was Jim forced to whitewash the fence? Or did he not whitewash it?

The potential conversational implicature, or whatever it is, fails to actualize as speaker meaning in the completely felicitous discourses (18b-d) because it would conflict with things the speaker is committed to or, in the case of (18d), she makes clear she is not committed to.

Two conclusions follow from these contrasts. First, presuppositions are quite different things than conversational implicatures even though both form part of what speakers mean. In particular, presuppositions are speaker commitments whereas conversational implicatures are not. Second, the FOS Test as usually applied does not distinguish conversational implicatures from presuppositions.

The fact that conversational implicatures, when present, are part of a speaker's meaning together with the fact that they pass the FOS Test as usually applied opens the door wide to the possibility of confounding conversational implicatures with presuppositions. Theorizing about presuppositions and their projection in the latter 1970s brought forth numerous proposals that presuppositions are conversational implicatures, or at least close relatives of them (e.g., Atlas, Boër, Kempson, Levinson, Lycan, Wilson). A clear understanding that not all speaker meaning rests on a speaker commitment brings out why this initially appealing approach to presupposition cannot ultimately succeed: presuppositions are in fact speaker commitments.

Of course, today's far more extensive empirical grasp of data concerning projection of various types of content was not available then. Now we can see that a wide

3 For a discussion of how the implication could arise as meant by a speaker of (17b), see Karttunen 2016: §3.3.1. 
Presupposition

range of varieties of propositional content that are distinct from asserted content project in patterns that are similar but not identical to each other.

\subsection{Karttunen's (1973) refinement of presupposition projection}

Although Langendoen \& Savin (1979) proposed that presuppositions project to expressions cumulatively from expressions they contain, Karttunen showed definitively in (1973) that projection is not as simple as this. While presuppositions project from the antecedent of conditionals, as illustrated earlier, they do not always project from the consequent of a conditional. For instance, the presupposition of (19) that Mary has a brother, which is associated with the definite possessive in (19), does not project in (20).

(19) Mary won't let her brother be bullied.

(20) If Mary has a brother, she won't let her brother be bullied.

The felicity of (21) shows that (20) lacks this presupposition.

(21) I'm sure Mary doesn't have a brother; but if she does, she won't let her brother be bullied.

Note for comparison the deviance of (22), in which the presupposition does project from the conditional's antecedent.

(22) I'm sure Mary doesn't have a brother. \#But if she won't let her brother be bullied, that is admirable.

Karttunen demonstrated that presuppositions of a conditional's consequent clause are selectively filtered. All project except those that are hypothetically supposed in the antecedent clause. Intuitively (23a) commits the speaker to Mary having a brother; and the deviance of discourse (23b) confirms this intuitive judgment.

(23) a. If I know Mary, she won't let her brother be bullied.

b. I'm sure Mary doesn't have a brother. \#And if I know Mary, she won't let her brother be bullied.

Related observations, only a little more complex to describe, concern presupposition filtering in coordinations with the conjunctions and and or.

These departures from cumulative projection of presuppositions are highly regular. Any description of the phenomenon of presupposition must capture them, and they constitute a important touchstone: any theory of presupposition must account for them. 


\subsection{Conventional implicatures}

Grice himself pointed to the existence of speaker commitments that are not part of asserted content. ${ }^{4}$ These he termed conventional implicature (1989). ${ }^{5}$ Conventional implicatures also pass the FOS Test as commonly applied, projecting similarly to presuppositions as well as to conversational implicatures.

(24) a. Huck, that michievous rascal, dipped Becky's pigtail in the inkwell \#and Huck isn't a mischievous rascal.

b. Huck, that michievous rascal, didn't dip Becky's pigtail in the inkwell \#and Huck isn't a mischievous rascal.

c. If Huck, that michievous rascal, dipped Becky's pigtail in the inkwell, the teacher punished the wrong pupil; \#but Huck isn't a mischievous rascal.

d. Did Huck, that michievous rascal, dip Becky's pigtail in the inkwell? \#I'm aware that Huck isn't a mischievous rascal.

As the deviance of (24a-d) demonstrates, conventional implicatures are a variety of speaker commitment, like presuppositions.

Karttunen \& Peters (1979) proposed that many presuppositions are in fact conventional implicatures, a view that is not widely accepted today. While the two varieties of speaker commitment share a number of characteristics, they are thought to differ sufficiently that many scholars believe they are distinct species. One more characteristic they share is that both are subsidiary speaker commitments rather than primary ones, as shown by the contrasts in the following question/answer pairs.

Q: Did someone offend Sue?

A1: \#It was James who offended Sue.

A2: James offended Sue.

(26) Q: Was Dewey a New Yorker? And who ran against Truman in 1948?

A1: \#Dewey, who was a New Yorker, ran against Truman in 1948.

A2: Yes, Dewey was a New Yorker, and it was he who ran against Truman in 1948.

In each case answer A2 commits the speaker to the same propositions as answer A1. But committing to responsive information in a subsidiary manner, as a presupposition or a conventional implicature, is often infelicitous in answering a question. Often, though not always as we shall later see, for the answer to be felicitous speakers should make a primary commitment to the information requested.

4 Being speaker commitments, they perforce are not conversational implicatures.

5 Unhappily, in my opinion, as they are no more closely related to conversational implicatures than to asserted content, i.e., to what is said-in his terminology. 
Presupposition

\section{Patterns of projection}

The preceding subsections illustrated not only some commonalities but also some differences in the patterns in which presuppositions, conversational implicatures, and other types of non-asserted speaker meaning project. Both the commonalities and the differences are relevant to recent proposals that all content that projects should receive a unitary account of when and where it projects.

\subsection{Unitary projection?}

As Simons et al. 2010 put it,

While it is possible to analyze projection piecemeal, clearly a unitary explanation is to be preferred. Yet we show that standard explanations of projective behavior (common ground based theories, anaphoric theories, and multi-dimensional theories) do not extend to the full range of triggers. Instead, we propose an alternative explanation based on the following claim, which is intended to apply to all content which occurs in embedded contexts: Meanings project IFF they are not at-issue, where at-issueness is defined in terms of the [sic] Roberts' (1996) discourse theory. Thus, and despite their apparent heterogeneity, projective meaning triggers emerge as a natural class on the basis of the not at-issue status of their projective inference.

(emphasis added). The authors' stated purpose in this paper is to tie projection intimately to discourse structure. They intend their "claim that projection is a consequence of the scope of sentential operators such as negation, conditionals and modals typically being limited roughly to what is understood as the main point, or, in the terminology we will use, the at-issue content of the utterance" to make the desired linkage. "Whatever does not belong to the main point - the not-at-issue content - is left out of the scope of the operator, and hence projects." Explicitly, "the specific hypotheses we will defend are these:

[= their (12)] Hypotheses about what projects and why

a. All and only those implications of (embedded) sentences which are notat-issue relative to the Question Under Discussion in the context have the potential to project.

b. Operators (modals, negation, etc.) target at-issue content."

Evaluating this claim requires a clear understanding of two terms. 
- implication

- at-issue content

The former has to do with expressions such as clauses, and appears on its face to include asserted content, presupposed content, and conventionally implicated content. The latter has to do with utterances (speech acts) and discourse context. The property of content being at issue is defined by the authors in terms of relevance to questions under discussion in an utterance's context. Here is their definition of relevance.

(28) [= their (13)] "Relevance to the QUD

a. An assertion is relevant to a QUD iff it contextually entails a partial or complete answer to the QUD.

b. A question is relevant to a QUD iff it has an answer which contextually entails a partial or complete answer to the QUD."

The paper presents two non-equivalent definitions of content being at issue. "[T]he basic definition of at-issueness is:

[= their (14)]

A proposition $\mathrm{p}$ is at-issue relative to a question Q iff ?p is relevant to Q."

This definition makes proposition $p$ at issue wrt question $Q$ iff either $p$ entails a partial or complete answer to $Q$ or $\neg p$ entails a partial or complete answer to $Q$. The basic definition is strictly semantic-except to the extent that context brings propositions besides $p$ or $\neg p$ into answering $Q$.

(30) $\quad[=$ their (26)]

"Revised definition of at-issueness

a. A proposition $\mathrm{p}$ is at-issue iff the speaker intends to address the QUD via ?p.

b. An intention to address the QUD via ?p is felicitous only if:

i. ?p is relevant to the QUD, and

ii. the speaker can reasonably expect the addressee to recognize this intention."

This definition makes whether proposition $p$ is at issue (wrt question $Q$ ) entirely dependent on the speaker's intentions vis-à-vis addressing the question under discussion. Only secondarily does it introduce the possibility that such intentions of the speaker would be infelicitous if either $p$ is not relevant to the question (as defined in (28)) or it is unreasonable for the speaker to expect the addressee to recognize her 
intention. Obviously such a definition greatly complicates the problem of empirically evaluating claim (27) about when content projects.

A subsequent paper, Simons et al. 2016, undertakes to clarify the problem with a third way of characterizing exactly when $p$ is at issue: a statement's Current Question (CQ) does not entail $p$ and can be relevant to the context's Discourse Question (DQ) without the speaker believing $p$. The notion of a statement's CQ introduced in the paper refers, roughly, to the set of alternatives among which the speaker intends the statement to distinguish. This is a way of trying to define what question the speaker intends her statement to address. Relevance to the DQ, the question under discussion, is then assessed indirectly via the CQ: Does some answer to the CQ entail at least a partial answer to the DQ?

Simons et al. 2010's proposed unitary explanation of projection- "Whatever does not belong to the ...at-issue content ... is left out of the scope of the operator, and hence projects"- is at least partially retracted by Simons et al. 2016's assertion that "In ... Tonhauser et al. 2013, we demonstrated that there are several subtypes of not-at-issue, projective content. It is entirely plausible that each subtype becomes projective through different mechanisms." (emphasis added) Accordingly, the next section's discussion is organized around the claimed generalization as much as their proposed explanations of it.

\subsection{Assessing the unitary hypothesis}

The claim that content of a clause projects if and only if it is not at issue in the discourse context is a bold generalization. Obviously it can only be substantiated through meticulous clarification and thorough empirical evaluation. A very basic check on its viability would be to show it explains the kind of selective filtering of presuppositions Karttunen (1973) discovered (see section 1.3). However, this key challenge has not been met to date.

My purpose here is not a detailed assessment of Simons et al.'s proposals in light of their varying definitions of what is at issue in the context of a given utterance. Rather I first present two empirically grounded observations that directly conflict with the generalization they state and aim to explain, that is with (31).

(31) Propositional content of an embedded clause projects IFF it is not at issue in the context.

I then point out a fundamental conflict at the heart of their argumentation.

One direct challenge to their generalization is the fact that presuppositions, and conventional implicatures as well, can project even when they directly answer an explicit question. As one example, Karttunen (2016: §4.2) shows that presuppositions project from temporal clauses as answers to direct questions. As another example, in 
discourse (32) the respondent answers a question with the projected presupposition: Billy is the neighbor kid who keeps ringing John's doorbell and running away.

(32) Q: Which neighbor kid keeps ringing John's doorbell and running away?

A: John is beside himself with frustration. He hasn't figured out it's Billy.

The projected proposition is clearly at issue in this context no matter how one hopes to formally define that intuitive notion. That (32A) commits its speaker to this presupposition is shown by the deviance of answering (32Q) with (33A).

(33) A: John is beside himself with frustration. He hasn't figured out it's Billy, \#and I'm quite sure it isn't.

This deviance stems from the explicit contradiction to which the answerer has committed herself, and the consequent the failure of (33A) to answer (32Q). So the left-to-right direction of (31) is not universally true. Being at issue doesn't always prevent content from projecting.

A second direct challenge is that not-at-issue meaning doesn't always project. Abundant clear examples exist. Consider just two. Statement (34a) has the implication that John has something chartreuse, and (34b) has the implication that the box was not wrapped just before the pre-utterance time referred to.

a. John has a chartreuse shirt.

b. Mary wrapped the box.

Both of these implied propositions are seldom ever at issue. Quite generally, in contexts where neither is at issue, (35a) does not indicate that John has something chartreuse.

(35) a. John doesn't have a chartreuse shirt.

b. Mary didn't wrap the box.

Nor does (35b) imply that the box was not already wrapped at the past reference time; stating (35b) usually says nothing about whether the box had wrappings during the period preceding the reference time. Like innumerable other propositions that form part of asserted content, these two usually do not project when they are not at issue.

This empirical fact and the preceding one constitute counterexamples to both directions of generalization (31). Neither a unitary explanation of projection nor piecemeal analyses can validate the generalization (quoted verbatim at the start of section 2.1) since the biconditional does not actually hold in either direction. So an analysis of projection that predicts generalization (31) has a strike against it for that very reason, rather than a point in its favor. 
Presupposition

A more fundamental problem with the unifying program stems from its failure to distinguish between speaker meaning and speaker commitment. As we saw in section 1, speaker commitments project even when projecting puts them in conflict with some aspect of utterance context. For example, (11), (12), (22), (23b), (24a-d), and nonmetalinguistic uses of (7) and (8) illustrate that projection of speaker commitments is not prevented by conflict with context. The only 'projected' propositions that speakers mean that cancel in contexts where they are at issue are not speaker commitments but things like conversational implicatures, as illustrated in section 1.2. For a proposition $p$ that would ordinarily project as a speaker commitment, $p$ being at issue in context does not stop it from projecting.

Presuppositions are not just speaker meaning but speaker commitments. This has the consequence that presuppositions cannot be blocked from projecting in virtue of being at issue in context. Neither can conventional implicatures. The flip side of this same coin is that treating a generalization like (31) as a projection mechanism inescapably fails to make projected propositions speaker commitments. It follows that (31) could not be the mechanism that projects presuppositions - or conventional implicatures - even if this biconditional were empirically unexceptionable. At most such a mechanism could project propositions to be speaker meaning. Even then a mechanism for producing speaker meaning which is as stipulative as biconditional (31) would compare unfavorably with, for example, Grice's explanation of how conversational implicatures arise.

The more restricted mechanism presented in Simons et al. (2016) for projecting the factive presupposition of sentences like (36) has greater potential to be explanatory—or would if it made the projected proposition a speaker commitment. ${ }^{6}$

Jane doesn't know it's raining.

This account, which requires speakers to believe it is raining but does not commit them to the proposition, is consistent with generalization (31) in not projecting the complement of "know" when it is at issue, while often projecting it when it is not at issue. $^{7}$ By not making the projected proposition a speaker commitment, however, the mechanism fails to project the proposition as a presupposition. Although the paper calls projected propositions "speaker commitments" throughout, it accurately likens its account of why speakers should believe projected propositions to Grice's analysis

6 A substantial literature has demonstrated that the verb "know" is not always factive. However, all examples discussed herein are.

7 The requirement for speakers to believe the complement of "know" when it is not at issue depends on the verb's veridicality. An empirical problem with the account is that "prove" also is veridical (entails that its complement is true), but unlike "know" is not factive. For example, stating (i),

(i) Stieltjes didn't prove that the Riemann Hypothesis is true.

does not require a speaker to believe that the Riemann Hypothesis is true. 
of conversational implicatures. The paper's confound of speaker meaning with speaker commitment is on vivid display in the following statement: "the interpreter's job is just to determine what the speaker is presenting as her commitments." Grice, in contrast, took pains to make clear that his account of conversational implicature via interpreters' reasoning explains interpreters' ability to recognize speaker meaning that is not a commitment.

Simons et al. 2016's disregard of the critical difference is crystalized in its account of how the speaker of (37A) communicates to the person who asked (37Q) that the car is parked in the garage, even though "believe" is not a factive verb.

Q: Why is it taking Phil so long to get here?

A: He didn't believe that the car's parked in the parking garage.

The proposed analysis of this case is, as the authors say, essentially similar to what their approach requires if "believe" is replaced by "know" in answer to this question. ${ }^{8}$ However, the lack of anomaly in discourses such as (38) shows that the two cases differ critically in what the respondent commits to. A speaker of (38A) is not required to believe the car is parked in the garage, whereas someone who said "know" instead of "believe" would be committed to this proposition.

Q: Why is it taking Phil so long to get here?

A: He didn't believe that the car's parked in the parking garage, and a good thing too. He just texted me that the garage attendants moved it to the street, where he finally found it.

When "know" is substituted for "believe" in (38A), a contradiction results.

(39) A: He didn't know that the car's parked in the parking garage, and a good thing too. \#He just texted me that the garage attendants moved it to the street, where he finally found it.

The deviance of this response shows that projection is not blocked in (39). Because the presupposition of "know" projects, a speaker who says "know" really is committed to the complement being true. It is erroneous to equate (i) the conversational implicature-like reasoning that indicates the complement clause is believed by a speaker who says "believe" in (37A) with (ii) the crucially different mechanism that projects the presupposition of "know" as a speaker commitment in responding with (39A) to question (38Q).

In summary, both papers' discussion of projection as a unitary phenomenon suffers from insufficient attention to when 'projected' propositions truly are speaker commitments, on the one hand, and when they are speaker meaning but not commitments, like conversational implicatures, on the other hand.

8 On their analysis, "know" would not automatically project its complement here. 
Presupposition

\section{Conclusion}

Section 1 argued that presuppositions and conventional implicatures are, like the assertive content of declarative sentences, propositions to whose truth speakers commit themselves. It also recalled Grice's argument that these types of speaker meaning differ substantially from conversational implicatures, which are a type of speaker meaning to whose truth speakers do not commit themselves. In combination these arguments yield the conclusion that an adequate theory of presuppositions and how they project over embedding constructions must give presuppositions the character of speaker commitments. Theories that don't are inadequate because they fail to capture an essential characteristic of presuppositions.

Section 2 argued that a prominent contemporary theory which aims to unify presupposition projection with projection of conventional implicatures, and even of assertive content, fails to make projected presuppositions speaker commitments. The conclusion that this theory is not adequate was further supported with evidence that assertive content which projects in situations for which this theory provides an account is genuinely not a speaker commitment; it is instead akin to conversational implicature: interpreter identifiable speaker meaning to which the speaker is not committed. Contrasting evidence showed that in a similar situation speakers are committed to projected presuppositions. Additionally, evidence was presented against the claim that content which is at issue never projects, as well as evidence against the proposition that all content projects if it is not at issue.

In conclusion, presupposition has different linguistic behavior than assertive content. Careful attention to the distinction between speaker commitment and speaker meaning that does not involve speaker commitment reveals that presuppositions' projective behavior is different from assertive content's. A theory of presupposition must explain why speakers are committed to projected presuppositions as much as they are to locally triggered ones. A theory of assertive content projection needs to explain how and when assertive content 'projects' without speakers being committed to it.

I observe in closing that there is no need for an explanation of how or why conversational implicatures 'project' when they do. Conversational implicatures associated with expressions in subordinate clauses only 'project' to a larger embedding sentence when Gricean reasoning applies to the full embedding sentence (see (17) and (18)).

\section{References}

Grice, H.P. 1989. Studies in the Ways of Words. Cambridge, MA: Harvard University Press. 
Karttunen, Lauri. 1973. Presuppositions of compound sentences. Linguistic Inquiry 4(2). 169-193.

Karttunen, Lauri. 2016. Presupposition: What went wrong? In Mary Moroney, Carol-Rose Little, Jacob Collard \& Dan Bergdorf (eds.), Semantics and Linguistic Theory (SALT) 26, 705-731. Ithaca, NY: CLC.

Karttunen, Lauri \& Stanley Peters. 1979. Conventional implicature. In Choon-Kyu Oh \& David Dineen (eds.), Syntax and Semantics, Vol. 11: Presupposition, 132-163. New York: Academic Press.

Langendoen, D. Terence \& Harris Savin. 1979. The projection problem for presuppositions. In Charles J. Fillmore \& Terence Langendoen (eds.), Studies in Linguistic Semantics, 373-388. New York: Holt, Rinehart, and Winston.

Simons, Mandy, David Beaver, Craige Roberts \& Judith Tonhauser. 2016. The best question: Explaining the projection behavior of factives. Discourse Processes 0(0). 1-20. doi:10.1080/0163853X.2016.1150660.

Simons, Mandy, Judith Tonhauser, David Beaver \& Craige Roberts. 2010. What projects and why. In Nan Li \& David Lutz (eds.), Semantics and Linguistic Theory (SALT) 20, 309-327. Ithaca, NY: CLC.

\footnotetext{
Stanley Peters

Stanford University

210 Panama Street

Stanford, CA 94305-4115

peters@stanford.edu
} 